\title{
Environment based Precision Agriculture
}

\section{Dr. Rohini. v}

Associate Professor, Department of Computer Science, CHRIST, Bangalore - 560029

Dr. V. B. Kirubanand

Associate Professor, Department of Computer Science, CHRIST, Bangalore - 560029 .

\section{Dr. Arokiasamy Soosaimanickam}

Associate Professor, Department of Information Systems, University of Nizwa, Sultanate of Oman

ABSTRACT

Agriculture, farming or animal husbandry is a vital occupation, since the history of mankind. The name agriculture represents all entities that came under the linear sequence of links of food chain for human beings. India is in an agricultural era, which is earning fame to it. In the fast moving world, agriculture should also run in the same pace along with the existing nature. This paper analyses the different methodologies for environment friendly precision agriculture. It comparesthevariousmethodsavailablefortheusageofmoderntoolsandtechniquesinagriculture in the digital world. It discusses an insight to dwell into the different techniques for intelligent farming in the digital world. It acts as a decision support system for the farmers to perform environment friendly smartarming.

Article Received: 10 August 2020, Revised: 25 October 2020, Accepted: 18 November 2020

\section{INTRODUCTION}

From the beginning, agriculture is crucial part of human society due to the reality that man and agriculture are directly related to each other. This fact leads towards the advancement and enhancement of the typical, inappropriate and time consuming methodologies, used for agriculture. The fast moving world, new trends and technological advancement has changed the life style of people. Emerging new technologies are becoming an important part of routine. Smart

homesandgrid,smartcities[1]smartcampus,ands martfarmingaresomeofthewholeadvanced and upgraded, information and communication technologies that are helping humans to savetime and get faster and aureate outcomes. Agriculture is the backbone of India, which is formed as an Indian Civilization.Our forefathers have framed the agricultural process with the climate, soil and rainfall. The early societies was well trained by word of mouth and had nutritional food according to the seasons in land and house. Early People were able to create their own tools according to their needs and made it permanent for the younger generation. The healthy and organic food created and taken by the ancient people made them to live long without any diseases. They had a balanced diet and energy to perform the same. Agriculture became the most predominant land use on the planet, feeding a booming population and transforming natural habitats of
manyspecies.Agriculture done by the farmers gave a positive vibe on the environment and boosted the local diversity. Farmers have maintained the flora and fauna of the rural areas for a millennium. Farm lands create wonderful variety of landscapes, ranging from beautiful fields of corn, cotton, paddyetc.

Agriculture helps to preserve valuable ecosystems. Agricultural systems that work in harmony with nature such as organic, or biodynamic farming create diverse natural habitats. Practices such as crop rotation, cover cropping, no-tillage and the application of compost, improve soil fertility naturally and can even speed up the soil formation. It avoids soil erosion and maintains the water level also. is rich in organic matter and flourishing with life also contain greater concentrations of the natural enemies of pests, thus supporting the growth of more crops.

Loss of soils is one of the biggest threats to our wellbeing, and intensive agriculture with monoculture fields is known to be one of its main contributors. Plants and trees in agricultural systems help to retain and add water to underground aquifers. This process is most effective when the crops being grown are perennials that continue to grow every year and have deep, well-established root systems. A successful strategy that has been applied already by our ancestors is to plant trees, bushes and grasses mixed together. By combining plants of different sizes, soils are 
evenly covered and can withstand heavy rains without being washedaway.Organicfarmingistheonlyalternativ eforfarmers,tosavetheirhealthandlifeofthesoil.Or ganic farming methods enable farmers to save money. It is possible to turn our own farm waste into value-added products like vermicomposting for increasing crop production. The poisoning of the land will be avoided and the soil enrichment will happen. We will be able to provide healthy food crops for our own consumption and for sale.Our

The bad returns from the agricultural land makes the farmers to sell the land for real estate business, which in turn causes the shortage of land for agriculture. People have started to grow organic plants in industries, where less place, more plants policy is used. Technology is the knowledge used to improve the productivity of crop production in agriculture. It is a combination and changes of the human labor, seeds, fertilizers, manure, animal labor and management from time to time. Technologies in agriculture developed to increase production, resolve chemo-physical, biological, socioeconomic constraints related to crop production.

The recommender system will provide the agricultural information about fertilizers, soil, climate, crop rotation, various government schemes and helping hand for business and solve the problems such as lack of information, advancement intechnology.

The advanced highly efficient, cost effective, sustainable, fast and aureate results have been the main factors which have invoked researchers' to contribute towards smart agriculture. E-farming, smart mobilized fertilization, RFID tags for cattle monitoring, GPS field monitoring, sensor networks in farming, moisture and humidity detection, context aware computing, precious farming, web of things and livestock and ware house management applications, etc.; are some of the technological projects related to the smart farming regime.

\section{Literature Review}

In [1], they were able to successively transmit, receive and record the data about the plants in their phones. The data sent consisted the readings of the moisture level, the area on which the water was
ON/OFF, the readings of the water level indicator etc. This same data was also recorded and made available in the form of graphs on ThingSpeak.

In [2], proposed an application that provides recommendations based on the timely information provided by the sensors as well as previous data from the database. This application is a combination of an IoT and Database Technology. This application will be helpful for the farmers to enroll and to be aware about the latest government schemes and crop related suggestion.

In [3], proposed a system based on ATMEGA328 arduino, which is found to be more compact, user friendly and less complex, which can readily be used in order to perform, several tedious and repetitive tasks. Due to the probability of high technology (Atmel microcontroller) used this is a fully software controlled with less hardware circuit. In [4], proposed a multidisciplinary approach for smart agriculture using five key technologies: Internet of Things, Sensors, Cloud Computing, Mobile Computing and Big-Data Analysis. Through real time sampling of soil farmer will be able to get current fertilizer requirements for the crop. This model facilitates the estimates of total production per crop region wise and state wise, total fertilizer requirements.

[5] Focuses on the prototype of a recommendation system, which works on a relatively small dataset, and can be used in an irrigation system. The amount of water in the soil is detected by a sensor and if the water level is below a certain level, then the farm can be irrigated automatically, from a water reservoir in the farm, which is been used by many farmers for automatic switching on the motor.

[6] Proposes a framework called Smart Agriculture that consists of smart devices, WSN, and Internet by which agricultural processes will be automated. The farmer can ON/OFF the devices like water sprayers, drip irrigators, by his smart phone. The system will predict the global market for the crop harvest and sales, which will improve the Gross Domestic Product (GDP) of the country.

[7] Gives an analysis of the soil data using J48 algorithm and prediction methods. The J48 algorithm will analyse the report from the lab for the soil and gives recommendation for the cropping pattern and type to the farmer.

In [8], the purpose of this project was to design and build a working prototype to monitor and control the agricultural field. This system allows users to obtain temperature, humidity, light intensity and soil moisture readings on their smart phone as well as send the commands remotely. This was achieved using Arduino Uno (microcontrollers) and a 
Bluetooth (HC-05) wireless module. This is a cost effective, user friendly and reliable system.

[9] Gives a model that has been developed by integrated features of all the hardware components used. The moisture sensors measure the moisture level (water content) of the different plants. If the moisture level is found to be below the desired level, the moisture sensor sends the signal to the Arduino board which triggers the Water Pump to turn $\mathrm{ON}$ and supply the water to respective plant using the Rotating Platform/Sprinkler. When the desired moisture level is reached, the system halts on its own and the Water Pump is turned OFF.

[10] Proposes an automatic system that will precisely monitor and control the water requirements in the field. This architecture uses microcontroller which promises an increase in system life by reducing power consumption and water consumption.

The system uses a Bluetooth for remote monitoring which reduces the problem of range with GSM network and saves SMS cost for the farmer. The smoke sensors used to send emergency information to user in case of fire in field or burning of motor. The design is low power, low cost, small size, robust and highly versatile [11].

\section{Impact of the Trend}

Agricultural technology uses machines, which are a replacement of humans that are designed for every stage of the agricultural method. Machines are used for tilling the soil, planting seeds, irrigating the farmland, cultivating crops and also to protect the crops from pests. Robotic technologies enable more reliable monitoring and management of natural resources, air and water quality.

The process of change in agriculture technology has gone thru the below stages:

- Changes in farm machinetechnology

- Changes in animal productiontechnology

- Changes in plant productiontechnology

- Changes in land usetechnology

- Changes in food and fiber processingtechnology

Agriculture e -marketing

- Web portals

- Direct consumer and retailerinteraction

- Online availability

- Improved socialapproach

- $\quad$ E-store

Improved economic condition, direct interaction between two parties, discarded communication gap and marketing of surplus products.

\section{Farmers}

- Controlled and automated farmfields.

- Hot linesupport

- $\quad$ On time pesticide and other fault detection by using differentsensors.

- $\quad$ Always connected to the farm by smartphones.

- $\quad$ Alarm support andmonitoring

Farming

- $\quad$ Smart irrigationsystem

- Weather and humiditydetection

- Trackingsystem

- $\quad$ GPS and satellite enabled monitoring

- $\quad$ Smart application for pesticide and fertilizer applications

- $\quad$ Smart security forfield

- Smart automatedmachinery

- $\quad$ Actuated nodes forfarms

- $\quad$ Smartharvesting

- $\quad$ Soil monitoring

Improved hand tools, advanced irrigation practices, improved storage, better productivity, development in machines mechanically e.g. power, tractors, and equipment, mechanical harvesters, Irrigation system, reclamation, development in the tools and equipment fordifferent Product testing. Improvedquality.

\section{Different irrigation methods}

"One of the biggest farming challenges in India is irrigation," says co-founder of agritech startup Avanijal, Vijayeendra H S. "Farmers generally use drip or sprinkler systems, which typically wastes water and can often over-irrigate crops, affecting the final yield," he adds.

There are different types of method for irrigating farm field for different types of crop field. Basically Indian farmer use three methods for irrigation, sprinkle irrigation, channel system and drip irrigation. Channel system is used for irrigation of large areas. This system requires a large number of laborers and high amount of water wastage. Sprinkler and drip irrigation are costlier

thanchannelbuttheyarewater,timeandlaborerssav ing.Butasmartirrigationsystemwasanew technology to irrigate farm technology. Out of the other methods used, smart irrigation systems weremoreuseful.Dripandsprinklesystemsaregene rallyoperatedbyauser, butasmartirrigation systemtellsthatthetotalsystemiscontrolledbyauto mation.Theirrigationisdonewhetherornot 
thefarmerispresentinthefield.Soilmoisturesensori ncludesacomparator.Thesoilbetweentwo probes acts as variable resistance whose value depends on moisture content in the soil. Soil moisture sensors are used to sense the moisture level in soil and then the irrigation is done accordingly. The output sensor value is compared with the fixed value in the comparator LM 393 and signal is transmitted for further processing in microcontroller ormicroprocessor.

Theusageofwaterefficientlyunderaconventionalfl oodoftheirrigationsystem, isverylowdue to substantialconveyance.

New and Latest Technologies in Agriculture Artificial intelligence/Machine Learning / Deep learning methods

Artificial Intelligence tools are used for weather prediction, types of harvest a crop would need, and the type of soil most suitable. Machine learning is a trending technology nowadays and it can be used in modern agriculture industry. The uses of ML in agriculture helps to create more healthy seeds. Artificial machine learning techniques are being used in the agricultural sector to increase the accuracy and to find solutions to the problems. In machine learning agriculture, the methods are derived from the learning process. These methodologies need to learn through experiences to perform a particular task. The ML consistsof data that are based on a set of examples. An individual example is defined as a set of attributes. These sets of characteristics are known as variables or features. A feature can be represented as binary or numeric or ordinal. The performance of the machine learning is being calculated from the performance metric. To determine the performance of ML models and the machine learning algorithms agricultures various mathematical and statistical models are used. Once the learning process is completed, then the model can then be used to make an assumption, to classify and to test data. This is achieved after gaining the experience of the trainingprocess.

Various applications of machine learning in agriculture

\section{Agriculture Robot}

Robots are used to handle the essential task related to agriculture. This includes harvesting crops and works faster than then human laborers. This is the best example of machine learning in agriculture. Companies are now making use of technologies and deep learning algorithms. The data are then collected using the drones and other software to monitor the crops and also the soil. They also use the software to control the fertility of the soil. The agricultural farmers are now taking advantage of the machine learning models and their innovations. The Farmers Business Network that is being created for the farmers a social network will make use of the ML and the analytic tools to drive the results of data on pricing. Robots are now managing the crops and also monitoring them. Sensors are helping to collect the data related to crops.According to research if $\mathrm{AI}$ and ML are being used in agriculture, then the agriculture sector will grow in the coming years.

There is a rise in digital agriculture, which uses a secured approach to give maximumagricultural productivity by reducing the impact on the environment. The date that is generated in modern agriculture is based on various sensors that will help in better understanding of an environment likethecrop,soilandtheweatherconditionsandalso abouttheagriculturalmachines.Thesedata will help us to take quick and fast result-oriented decisions. To yield more, we need to apply machine learning to agriculturedata.

The machine learning tools which were reserved for some institutions are now accessible to all small and capable members. A small startup is making use if $\mathrm{AI}$ and machine learning to bring change in the modern agriculture sector. They are trying to reshape the contemporary agriculture sector by making use of innovative technologies.

\section{Mobile Applications}

Smart phones are reachable by all people, the deep penetration of digitization was felt across the

country.Useofmobilephonestoscantheplant,soil,t oanalyseandrecommendtheneedfulthings.For Precision Farming or Smart Farming, drones bring efficiency with accurate information reducing uncertainty while decision making. Buying the correct sensors, drones can provide farmers with real-time information regarding crops, soil deterioration, dry regions, fungal infections etc. The information collected from the land can be intimated to the farmers to implement the suggestions for irrigation and better techniques.

\section{Sensors}

Features which have to be considered when we choose a sensor are: 
1. Accuracy

2. Environmental condition - usually has limits for temperature/humidity

3. Range - Measurement limit ofsensor

4. Calibration - Essential for most of the measuring devices as the readings changestime

5. Resolution - Smallest increment detected by thesensor

6. Cost

7. Repeatability - The reading that varies is repeatedly measured under the sameenvironment

\section{Types of sensor deployment in precision} agriculture:

\section{Location Sensors}

These sensors use signals from GPS satellites to determine latitude, longitude, and altitude to within feet. Three satellites minimum are required to triangulate a position. Precise positioning is the cornerstone of precision agriculture. GPS integrated circuits like the NJRNJG1157PCD-TE1 are a good example of location sensors.

\section{Optical Sensors}

These use light to measure soil properties. The sensors measure different frequencies of light reflectance in near-infrared, mid infrared and polarized light spectrums. Sensors can be placed on vehicles or aerial platforms such as drones or even satellites. Soil reflectance and plant color data are just two variables from optical sensors that can be aggregated and processed. Optical sensors have been developed to determine clay, organic matter, and moisture content of the soil. Vishay,

forexample,offershundredsofphotodetectorsandp hotodiodes, abasicbuildingblockforoptical sensors.

\section{ELECTROCHEMICAL SENSORS}

It provides key information required in precision agriculture: $\mathrm{pH}$ and soil nutrient levels. Sensor electrodes work by detecting specific ions in the soil. Currently, sensors mounted to specially designed "sleds" help gather, process, and map soil chemical data.

\section{MECHANICAL SENSORS}

These are used to measure soil compaction or "mechanical resistance." The sensors use a probe that penetrates the soil and records resistive forces through use of load cells or strain gauges. A similarformofthistechnologyisusedonlargetracto rstopredictpullingrequirementsforground engagingequipment.

\section{IoT (INTERNET OF THINGS)}

The Internet of things (IoT) is the internetworking of physical devices, vehicles (also referred to as "connected devices" and "smart devices"), buildings and other itemsembedded with electronics, software, sensors, actuators, and network connectivity that enable these objects to collectandexchangedata.In2013theGlobalStanda rdsInitiativeonInternetofThings(IoT-GSI) defined the IoT as "the infrastructure of the information society. "The IoT allows objects to be sensed and/or controlled remotely across existing network infrastructure, creating opportunities for more direct integration of the physical world into computer-based systems, and resulting in improved efficiency, accuracy and economic benefit. When IoT is augmented with sensors and actuators, thetechnologybecomesaninstanceofthe moregeneralclassofcyber-physicalsystems, which also encompasses technologies such as smart grids, smart homes, intelligent transportation and smart cities. Each thing is uniquely identifiable through its embedded computing system but isabletointeroperatewithintheexistingInternetinfr astructure.ExpertsestimatethattheIoTwill consist of almost 50 billion objects by 2020 .

RadioFrequencyIdentification(RFID)technology mainlyidentifiesanobjectbyreadiofrequency without anycontact.

\section{Irrigate via Smartphone}

MobileTechnologyplaysanimportantroleinmonit oringandcontrollingcropirrigationsystems.

Withthe correct type of equipment, afarmercancontrolirrigationsystemsf romaphoneorcomputer instead of driving to the field irrespective of thedistance.

\section{CONCLUSION}

By applying machine learning to sensor data, farm management systems are evolving into real artificial intelligence systems, providing richer recommendations and insights for the subsequent decisions and actions with the ultimate scope of production improvement. For this scope, in the future, it is expected that the usage of ML models will be even more widespread, allowing for the possibility of integrated and applicable tools. At the moment, all of the approaches regard individual approaches and solutions and are not adequately connected with the decision-making process, as seen in other application domains. This integration of automated data recording, data analysis, ML implementation, and decision- 
making or support will provide practical tolls that come in line with the so-called knowledgebased agriculture for increasing production levels and bio-products quality.

Data analysis, as a mature scientific field, provides the ground for the development of numerous applications related to crop management because, in most cases, ML-based predictions can be extracted without the need for fusion of data from other resources. In contrast, when data recordings are involved, occasionally at the level of big data, the implementations of ML are less in number, mainly because of the increased efforts required for the data analysis task and not for the ML models per se.

\section{REFERENCES}

1. Hariharr C Punjabi, SanketAgarwal, VivekKhithani and VenkateshMuddaliar, SMART FARMING USING IOT, International Journal of Electronics and Communication Engineering and Technology(IJECET)

Volume 8, Issue 1, January - February 2017, pp. 58-66

2 PrathmeshShirshivkar, MayurSolaskar, Ramesh Borkar, Sameer Sawant, SmitaPatil, Recommender System For Smart Agriculture Using Iot, IOSR Journal of Engineering (IOSR JEN), ISSN (e): 2250-3021, ISSN (p): 22788719, PP 42-44

3. Chatterjee, K. O. U. S. I. K., \&Dasgupta, S. A. B. U. J. (2016). Information seeking behavior of agricultural researcher while using internet: a case study of bidhanchandrakrishiviswavidyalaya central library, west bengal, india. International Journal Of Library \& Educational Science, 2(4), 11-20.

4. Ahadit, Aravindkumar, Balaji, Hariprakash, Satheesh, ENVIRONMENT BASED IRRIGATION SYSTEM USING WIRELESS TECHNOLOGY, International Research Journal of Engineering and Technology (IRJET) e-ISSN: 2395-0056 Volume: 05 Issue: 01, Jan-2018,Page991

5. Saravanan, S., Aravinth, S. S., \&Rameshkumar, M. (2017). A Novel Approach in Agriculture Automation for Sugarcane Farming by Human Assisting Care Robot. 2017).
International Journal of Agricultural Science and Research (IJASR) 7.4, Aug 2017, 107, 112.

6. HemlataChanne, Sukhesh Kothari, DipaliKadam, Multidisciplinary Model for Smart AgricultureusingInternet-ofThings(IoT),Sensors,Cloud-

Computing,Mobile-Computing \& BigData Analysis, International Journal of Computer Technology andApplications,

7. , Vol 6 (3), Page 374-382

8. Tanmay Banavlikar1, Aqsa Mahir2, Mayuresh Budukh3, SohamDhodapkar, CROP RECOMMENDATION SYSTEM USING NEURAL NETWORKS, International ResearchJournalofEngineeringandTech nology(IRJET)e-ISSN:2395-

0056Volume:05 Issue: 05, May-2018, Page 1475

9. Patel, A. H. (2015). Electrical Conductivity in Relation With MacroMicro Nutrients of Agricultural Soil of Amreli District. Best Journals, 3(8), 25-30.

10. Dr. Mahesh K Kaluti, Shashank A R, GovindaRaju Y, Harshith $\mathrm{K} S$, Farmer's friend: Utilization of IoT and Web application in Agriculture, International Research Journal of EngineeringandTechnology(IRJET)eISSN:2395-

0056Volume:05Issue:03,Mar-2018, Page 1432

11. Dasore, A., Konijeti, R., \&Puppala, N. (2018). A panorama of ideas in the adoption of an effective and efficient drying technique for an agricultural produce. International Journal of Mechanical and Production Engineering Research andDevelopment (IJMPERD), 8(2018), 955-962.

12 Pooja M C, Sangeetha M, Shreyaswi J Salian, VeenaKamath, MithunNaik, Implementation of Crop Yield Forecasting Using Data Mining, International Research JournalofEngineeringandTechnology(I RJET)e-ISSN:23950056Volume:05Issue:04

13. |Apr-2018, Page 2057

14. Samarth Mehta, NamrataSaraff ,SahilSawant Sanjay ,ShailyPandey, Automated Agricultural Monitoring and Controlling System Using HC05 
BT Module, International ResearchJournalofEngineeringandTech nology(IRJET)e-ISSN:2395-

0056Volume:05 Issue: 05 | May-2018 www.irjet.net p-ISSN: 2395-0072 (c) 2018, IRJET | Impact Factor value: 6.171 | ISO 9001:2008 Certified Journal | Page1560

15. DIN, T. M. U. HANDICRAFT ENTREPRENEURSHIP: TOOL FOR ECONOMIC DEVELOPMENT IN RURAL ECONOMY.

16. S. V. Devika, Sk. Khamuruddeen, Sk. Khamurunnisa, JayanthThota, KhaleshaShaik, "Arduino Based Automatic Plant Watering System", International Journal of Advanced Research in Computer Science and Software Engineering, pp. 449-456 Volume 4, Issue 10, October2014

17. KUMAR, S. R., KALYAN, H. S., KUMAR, K. D., \&Dilip, S. (2018). Design and fabrication of autonomous robot for precision agriculture.

18. S.Darshna,T.Sangavi,SheenaMohan,A. Soundharya,SukanyaDesikan,"SmartIrr igation System", IOSR Journal of Electronics and Communication Engineering (IOSRJECE) eISSN:2278-2834,p-ISSN:2278-

8735. Volume10,Issue3, Ver.II(MayJun.2015),PP32- 36

19. PavithraD.S,M.S.Srinath,"'GSMbasedA utomaticIrrigationControlSystemforEff icient UseofResourcesandCropPlanningbyUsi nganAndroidMobile",IOSRJournalof MechanicalandCivilEngineering(IOSR -JMCE)eISSN:2278-1684,pISSN:2320-334X, Volume 11, Issue 4 Ver. I (Jul-Aug. 2014), PP49-55

20. BishnuDeo Kumar, PrachiSrivastava, ReetikaAgrawal, VanyaTiwari, "MICROCONTROLLER BASED AUTOMATIC PLANT IRRIGATION SYSTEM", International Research Journal of Engineering and Technology (IRJET) e-ISSN:2395 